EPJ Web of Conferences 98, 06003 (2015)

DOI: $10.1051 /$ epjconf/ 20159806003

(C) Owned by the authors, published by EDP Sciences - SIF, 2015

\title{
Integrated assessment for supporting decision making with multiple criteria
}

\section{R. FRIEDRICH}

Institute for Energy Economics and the Rationale Use of Energy (IER)

University of Stuttgart - Stuttgart, Germany

Summary. - Decisions about the development of the energy system should take all relevant criteria into account, including costs and health, environmental and climate impacts. As usually no decision alternative fulfils all criteria better than all other alternatives, a weighting between the indicators that show the degree of fulfilment of the criteria, is necessary. In the following the "impact pathway approach" is described that supports decisions by using weighting factors that are derived from measuring or observing the preferences of the population. The methodology is applied to rank technologies for generating electricity according to their social costs, which is a summary indicator comprising simultaneously costs, impacts of air pollution on health and biodiversity and climate impacts.

\section{1. - Introduction}

In the following, the use of a quantitative tool to support decisions about changes in the energy system will be recommended. Such decisions could be

Which technology should be chosen to meet an additional demand (of electricity or heat)?

Which techniques/systems should be subsidized or penalised?

What are the weak points of a technology? Which features of a technique should be improved by research and development?

This is an Open Access article distributed under the terms of the Creative Commons Attribution License 4.0, which permits unrestricted use, distribution, and reproduction in any medium, provided the original work is properly cited. 


\section{EPJ Web of Conferences}

To show the necessity of having a quantitative tool for supporting decision making under multiple objectives, we first discuss, how according to newer psychological findings we form opinions and make decisions. We here mainly follow the arguments of psychologist Daniel Kahneman [1]. According to these new findings, we have a choice of using two internal mechanisms when forming opinions (and making decisions based on these opinions). We nearly always use an intuitive system that produces answers/opinions quickly and effortlessly. It works automatically and unconsciously.

However, we also are able to use a "logical" mechanism, that first tries to collect all necessary and relevant information and then estimates the fulfilment of all relevant criteria. To use this system needs will power and high efforts. It cannot deal with more than one issue and is exhaustible. Thus usually we try to avoid using this mechanism.

Using the intuitive system produces decisions that are not optimal for our welfare. Problems are

- Opinions are based on the readily available information. Even if important information is missing, no attempt is made to collect it. The coherence of the information (a good story) is more important than quantity, quality and completeness of the information.

- Framing effect - the presentation of the information influences the opinion.

- HALO effect: one positive (or negative) characteristic of an option influences the perception of the other characteristics of the option.

- Complex questions are unconsciously replaced by simpler questions.

- Decisions/opinions of others (peers) influence our decisions/opinions.

The distorted opinion building is more prominent, if low frequencies or probabilities are involved. The human brain does not have means to grip the meaning of a low probability (say $10^{-6} / \mathrm{a}$ ) that an event occurs. Problems are

- Low probabilities/frequencies are weighted over proportionally (risk aversion).

- The reduction of happiness due to a loss is higher than the increase of happiness due to a similar gain.

- Frequencies are estimated using the easiness of remembering an example for the damage.

It is obvious that decisions, that omit important information or do not account for the probability of an event, are not optimal, i.e. do not necessarily lead to optimizing welfare. Now decisions in the energy field are not made by single individuals and not made totally intuitive, usually studies and analyses are made before deciding. However, a number of problems remain. First, decision makers are part of a group, e.g. of a political party. Thus they will be heavily influenced by the opinions of the group. Secondly, while information about the effects of a decision might be available, the decision is still made intuitively by 
a decision maker or a group of decision makers with the typical strategies, e.g. making a decision by simplifying the problem and then trying to weigh the different arguments in such a way, that the original intuitive decision is justified. Thirdly, regardless of the opinion of a well-informed policy maker, he cannot decide against the intuitive opinion of the majority of the public and the media, as otherwise he would not be re-elected.

Thus it is obvious, that - to contribute to the fulfilment of the ultimate aim of policy making, which is increasing the happiness of the population - at least for public decisions a quantitative assessment/decision support system should be used that is consistent and discloses the decision process in a reproducible and comprehensible way.

In the following, I will present a decision support system that is capable of carrying out an integrated assessment of technical energy systems or energy policies. An integrated assessment is a multidisciplinary process of synthesizing knowledge across scientific disciplines with the purpose of providing all relevant information to decision makers to help to make decisions.

Decisions about energy systems usually should be made taking into account at least the following criteria:

Costs to society as a whole should be small.

Greenhouse gas emissions should be low.

Health impacts and impacts on natural ecosystems (biodiversity) should be low.

Energy security should be high, dependence on supply from non-EU countries should be low.

One could argue that distributional effects also matter; however distributional effects can always be changed by accompanying measures, e.g. additional taxes or social spending.

Thus an integrated assessment should at least consider the four criteria mentioned above. However, for energy security no meaningful indicator can be quantified. Energy security should be expressed as the expectation value of GDP reduction caused by unforeseen events that increase the scarcity of energy carrier and thus the price of the resource multiplied with the frequency with which such events occur. Obviously it is not yet possible to quantify this damage. Thus energy security can only be considered qualitatively by describing the share of the resource that is imported and the regions where the source comes from.

The task is thus to support decisions taking into account costs, impacts on public health, ecosystems and materials caused by air pollution and accidents and impacts on the climate. In the following the methodology used is demonstrated by applying it to an example, the assessment of different technologies to generate electricity.

\section{2. - Electricity generating costs}

Electricity generating costs contain all costs that society has to bear. These do include costs for investment, operation, repair and maintenance, fuel, auxiliary supplies, waste 


\section{EPJ Web of Conferences}

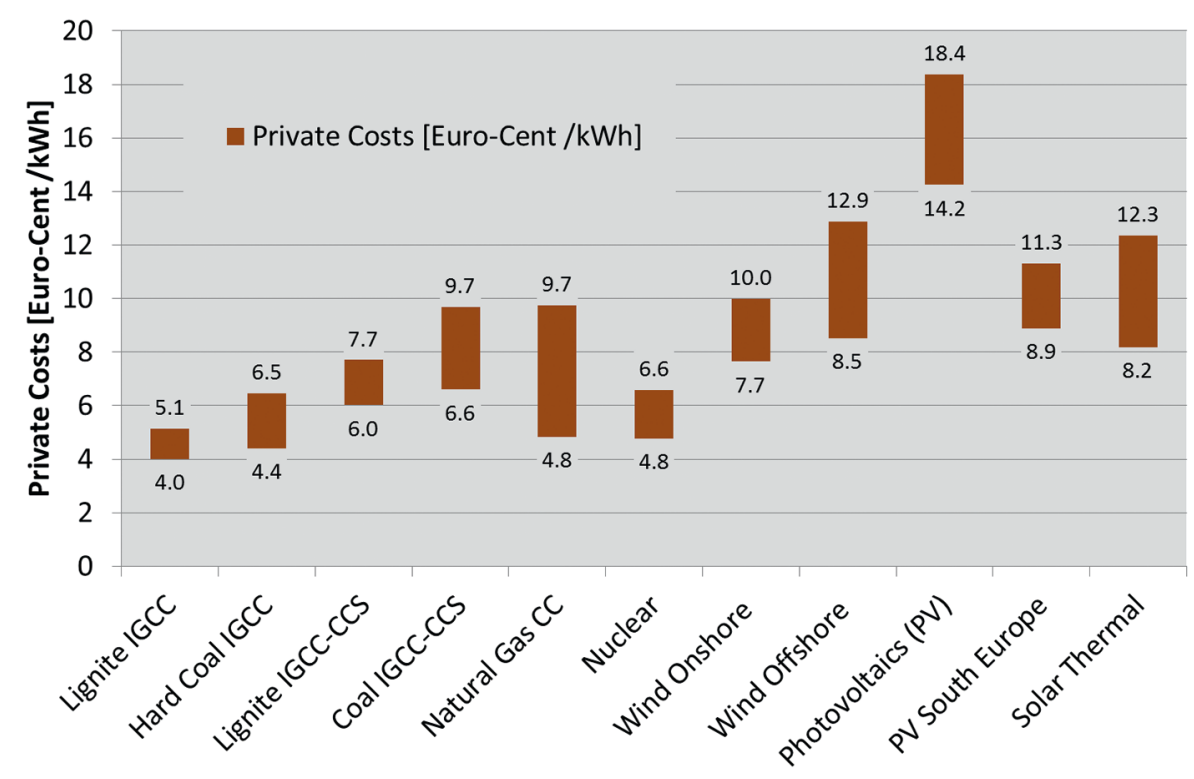

Fig. 1. - Electricity generating costs for new power plants with the first year of operation in 2025, back-up costs are included. IGCC = integrated gasification combined cycle, $\mathrm{CCS}=$ carbon capture and storage.

disposal and dismantling. Taxes paid by the electricity company are not included, as these are simply transfers of money to the state. What is however included are so-called back-up costs. Especially renewable energies like wind and photovoltaic do not generate electricity, when it is needed, but when the wind is blowing or the sun is shining. Thus it is necessary to install a back-up system that is capable to provide electricity at times when renewable energies are not available. These back-up systems could be systems that store electricity or capacities of power plants using fossil fuels. Economically feasible storage systems are especially pumped storage hydro power plants, however there is only a limited capacity for additional plants. Thus here we estimate the costs for providing the reserve capacity with coal fired reserve plants. These costs are then assigned to the renewable plants. Basically this is done by constructing two electricity generating systems, one with the renewable energy technology and one without it (reference case). Both systems have to provide electricity according to the same temporal course of electricity demand over a year. The difference in costs between these two systems is then allocated to the renewable energy technique.

We want to support current and future decisions (and not assess past decisions), these will change the energy systems in the future. Thus we would need the features incl. costs, efficiency a.s.o. of future electricity generating techniques. To estimate the costs of future plants, we use a combination of two techniques. The first is a trend analysis. Based on the developments of costs in the past we extrapolate these cost changes to the future. 
Secondly, we carry out a technical analysis by analysing, whether new technological developments are discussed and likely to be realised. This includes e.g. CCS - carbon capture and storage - or integrated gasification combined cycle (IGCC) power plants. Such an analysis about future techniques was made within the EU research project NEEDS (www.needsproject.eu), the results of this project are used here.

Figure 1 shows the costs per $\mathrm{kWh}$ produced for power plants that have the first year of operation in around 2025. As future costs are uncertain, an estimated uncertainty range is given represented by the bars shown. The plants are sited in central Europe, except "PV South Europe" and "Solar Thermal", which are built in Southern Europe. Lignite using the new IGCC technique is the cheapest option followed by hard coal IGCC plants. For nuclear plants, the new European Pressurized Water Reactor (EPR) concept is used. Uncertainties of the costs of natural gas plants reflect uncertainties especially of the future gas price. Onshore wind is the cheapest renewable option, while photovoltaics in central Europe, e.g. in Germany, would have far higher costs (with back-up costs) than the other analysed options.

\section{3. - Environmental health impacts}

The principal approach for estimating and monetizing impacts from environmental pressures is named "Impact Pathway Approach (IPA)" [2], the main elements of the approach are shown in fig. 2.

This methodology has been developed in a series of research projects funded by the European Commission, the "ExternE" project series (see www.ExternE.info). This methodology is widely used for environmental policy assessment, e.g. by the EC to justify environmental legislation with cost-benefit analyses, for example in the CAFÉ process, or for technology assessment, e.g. in transport for justifying large transport infrastructure projects. A documentation of the methodology can be found in [2]. The methodology is constantly updated, improved and extended, especially in the frame of EU research projects (recently, e.g., INTARESE, HEIMTSA, EXIOPOL, IN-STREAM, LC-IMPACT).

The results, i.e. the impacts per $t$ of pollutant released, depend on meteorology, land use, population density, height of release and concentration of other pollutants that react chemically with the released pollutant. Thus, the impacts depend on site and time of the release of substances and on stack height; the methodology considers this. This sitespecific analysis will be carried out for the substances with the highest impacts; these include PM10, PM2.5, $\mathrm{NO}_{x}, \mathrm{SO}_{2}, \mathrm{NMVOC}$ and $\mathrm{NH}_{3}$.

Starting with the emissions of the power plant and of the relevant up- and downstream processes, the transport and the chemical transformation of the pollutants in the atmosphere are calculated using a set of atmospheric models including a local model (ISC) and a simplified version of a European-wide Eulerian model, the Unified EMEP Model [3]. For the calculation of the chemical transformation of the gaseous substances into fine particles and ozone the concentration of all reagents of the chemical process has to be known, so all emissions of all sources, not only those of the analysed power 


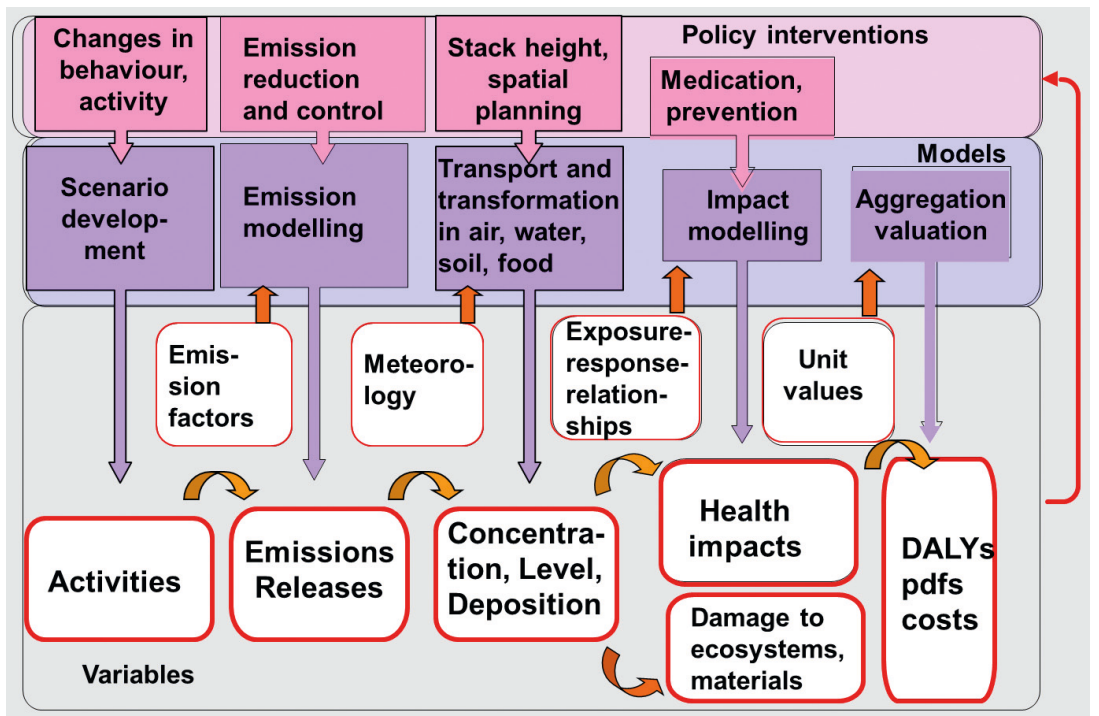

Fig. 2. - The impact pathway approach.

plant are needed as input. In fact, the calculation is made twice, first without and then with the emissions of the analysed power plant and the difference in the average annual concentration of fine particles and ozone is then used to estimate the additional health effect caused by the power plant.

The next step is the estimation of impacts to human health and the environment. The assessment of health impacts relies on results from epidemiological studies that analyse the relationship between changes in concentration and cases of illness. The used concentration-response functions have been selected by experts in epidemiology within a number of EC research projects NEEDS, HEIMTSA, INTARESE $[4,5]$. They represent the recommended state of the art set of concentration-response-functions regarding ambient air pollution of the air pollutants particulate matter and ozone in Europe (i.e. in the EU-28), that is used here. A detailed literature review, and the associated recommendations for CRFs and for background rates has recently been reported by WHO [6].

To illustrate how CRFs look like, table I shows some exemplary concentrationresponse functions (CRFs). Most morbidity risks occur shortly after inhalation. However, for chronic diseases, especially reduction of life expectancy and the occurrence of chronic bronchitis, this is different. After an exposure to fine particles for many years, a few of the exposed persons start to develop respiratory diseases and subsequently cardiovascular diseases that get chronic and - at the end of the life of the exposed person-lead to premature death. Thus, it is the life-long exposure to fine particles from many sources that at the end causes the reduction in lifetime.

Figure 3 shows the risks to human health caused by the production of one $\mathrm{kWh}$ in the power plants introduced in sect. 2. Health risks are shown as disability adjusted life years or DALYs. For each health endpoints - e.g. cough days or life years lost - the duration 
TABLE I. - Examples for concentration- response functions (SOMO35 is the Sum of Ozone Means Over $35 \mathrm{ppb}$, i.e. the yearly sum of the daily maximum of the 8-hour running average over $35 \mathrm{ppb}$.

\begin{tabular}{|l|c|c|}
\hline Pollutant and corresponding endpoint & $\begin{array}{c}\text { Health risk per person per } \\
\mu \mathrm{g} \text { per } \mathrm{m}^{3} \text { and year } \\
{\left[\mathrm{x} / \mu \mathrm{g} /\left(\mathrm{m}^{3} \times \mathrm{a}\right)\right]}\end{array}$ & Unit \\
\hline Particulate matter $<2.5 \mu \mathrm{m}$, i.e. PM2.5 & $6.51 \times 10^{-04}$ & years \\
\hline Life expectancy reduction - years of life lost & $1.39 \times 10^{-02}$ & days \\
\hline Work loss days (WLD) & $3.69 \times 10^{-02}$ & days \\
\hline Minor restricted activity days (MRAD) & \multicolumn{2}{|c|}{} \\
\hline Particulate matter $<10 \mu \mathrm{m}$, i.e. PM10 & $6.84 \times 10^{-08}$ & cases \\
\hline Increased mortality risk (infants) & $1.86 \times 10^{-05}$ & cases \\
\hline New cases of chronic bronchitis & $7.03 \times 10^{-06}$ & cases \\
\hline Respiratory hospital admissions (RHA) & $4.34 \times 10^{-06}$ & cases \\
\hline Cardiac hospital admissions (CHA) & & years \\
\hline Average daily SOMO35: Indicator for ozone & $2.23 \times 10^{-06}$ & cases \\
\hline Life expectancy reduction - years of life lost & $1.98 \times 10^{-06}$ & days \\
\hline Respiratory hospital admissions (RHA) & $7.36 \times 10^{-03}$ \\
\hline Minor restricted activity days (MRAD) & $1.04 \times 10^{-02}$ & days \\
\hline Cough days & & \\
\hline
\end{tabular}

as fraction of a year and the "severity" of the impact (from $0=$ healthy to $1=$ dead) are estimated, duration multiplied with severity gives the number of DALYs, one life year lost corresponds to one DALY. Please note that health impacts caused by upstream processes, e.g. the production of the plant, are included, thus wind and PV plants show some health impacts, although they do not emit pollutants in the operation phase. Not surprisingly, lignite and hard coal plants cause by far the highest health impacts.

For the nuclear reactor, the expectation value of health impacts caused by nuclear accidents is also included. Nuclear accidents with a high release of radioactive substances might cause a high number of latent fatalities; depending on the amount of the release and the weather conditions up to 52000 fatal cancers in a period of 100 years after the accident. However multiplied with the frequency of such an event (according to probabilistic safety analysis studies ca. $10^{-7}$ per year and reactor) and divided by the amount of $\mathrm{kWh}$ produced per year $\left(9.4 \times 10^{9} \mathrm{kWh} / \mathrm{a}\right)$ the expected value is negligible.

An estimation of impacts on ecosystems caused by different pollutants can be carried out by assessing losses of biodiversity as well as damages to crops and materials. Losses of biodiversity result from eutrophication and acidification of soil and water and can be 


\section{EPJ Web of Conferences}

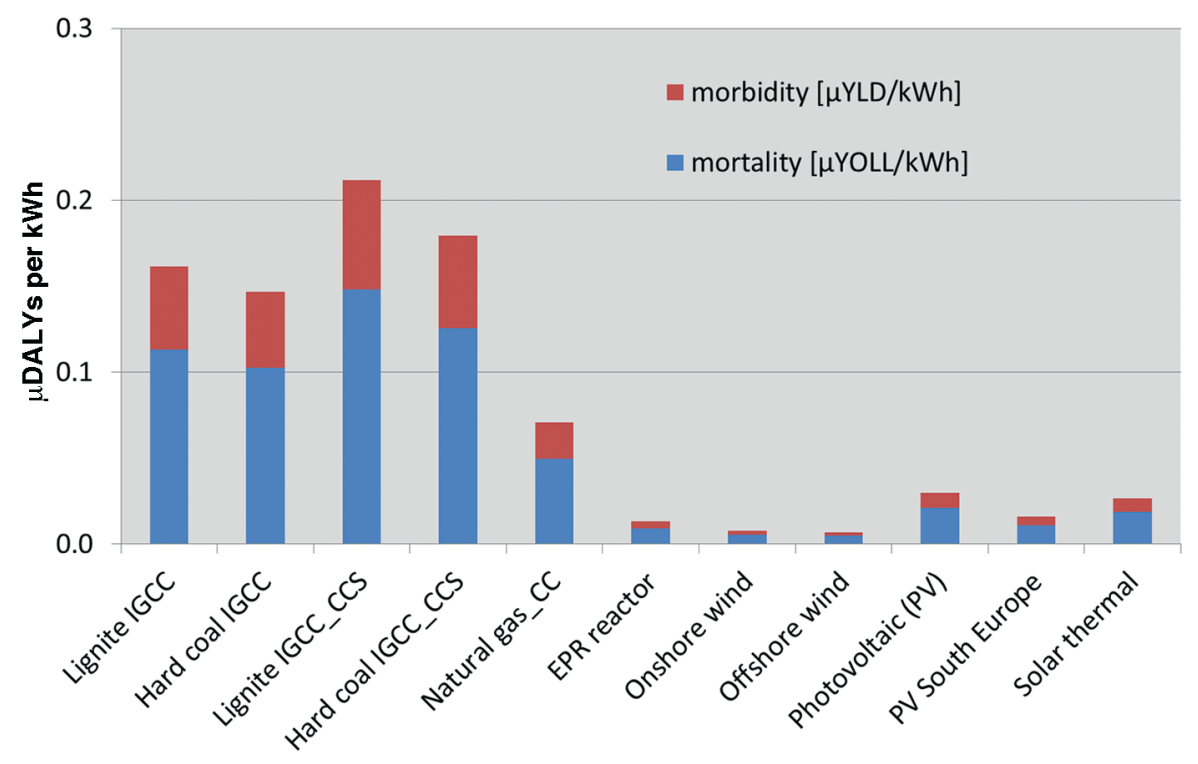

Fig. 3. - Health impacts caused by producing one $\mathrm{kWh}$ of electricity, including impacts of life cycle emissions and of accidents; YLD = years of life disabled $=$ DALYs; YOLL $=$ years of life lost $=$ DALYs.

roughly estimated by analysing the number of habitat species in a certain area. The indicator "potentially disappeared fraction of species" (pdf) in a certain area and a year can be calculated by comparing the richness in species in a reference scenario with a scenario including changes in pollution [7].

Having estimated health and environmental impacts, the next step of an assessment is to compare costs, non-monetary disadvantages and benefits to find out, whether the benefits of a policy or technology outweigh the costs or - if we have several alternative options - for which option the net present value of benefits minus costs is highest.

To be able to compare disadvantages and benefits quantitatively, they have to be available in the same measuring unit. Thus we need "weighting factors" that transform the physical impacts (additional number of chronic bronchitis) in a common measuring unit. For this unit, we use monetary values (e.g. $€_{2010}$ ), as this has a number of advantages. It allows the transfer of values measured in one study to other studies, as the monetary unit is defined independently of the study context. Furthermore, units are conceivable: it is directly clear, how much $1000 €$ is, but how much is a utility value difference of 1000 points? Thirdly, monetary values can be directly used for estimating eco-efficiency or within a cost benefit analysis.

To convert non-monetary impacts into monetary values, we use measurements of the preference of the affected population; e.g. we ask a representative part of the population about their willingness to pay to avoid a certain well-described risk or impact. In most cases, when assessing an impact, it is not necessary to carry out a new survey; instead, 
TABLE II. - Examples for monetary values of health endpoints.

\begin{tabular}{|l|rl|}
\hline Health End-Point & Central & Unit (2010) per case \\
\hline Increased mortality risk (infants) & 4485000 & Euro \\
New cases of chronic bronchitis & 60000 & Euro \\
Life expectancy reduction - Value of life year lost & 60000 & Euro \\
Respiratory hospital admissions & 2990 & Euro \\
Cardiac hospital admissions & 2990 & Euro \\
Work loss days (WLD) & 441 & Euro \\
Restricted activity days (RADs) & 194 & Euro \\
Minor restricted activity days (MRAD) & 57 & Euro \\
Lower respiratory symptoms & 57 & Euro \\
Cough days & 57 & Euro \\
\hline
\end{tabular}

the results of already existing studies for determining monetary values can be used.

Table II shows monetary factors used; these are valid for pressures occurring in 2010. Please note, that this does not mean, that e.g. the value of a life year is $60000 €$. Instead, it means, that the willingness to pay to avoid a small tolerable risk of for example $10^{-6} / \mathrm{a}$ to lose a year at the end of one's life is $10^{-6} \times 60000 €=0,06 €$. All monetary values calculated in this study are in money value 2010, i.e. inflation is not taken into account.

For the assessment of impacts due to emissions of air pollutants in future years an adjustment of the above presented values according to changes in the willingness to pay for avoiding health impacts becomes necessary. As described in [8], evidence was found, that monetary values for health risks for future years increase with an inter-temporal elasticity to GDP per capita growth of 0.7 to 1.0. An expected growth rate for the European economies of $2 \%$ per year has been assumed according to the expectations of the European Commission. This growth rate will be combined with an elasticity of 0.85 for the next 30 years. The resulting factor for uplifting WTP for 2020 from 2010 values is for example 1.1836 .

The actual application of the impact pathway approach is carried out using a webbased computer tool called ECOSENSE (www.externe.info). This tool exists in two versions. The more complex version "EcoSenseWeb" takes the concrete location of the power plant into account when applying the local atmospheric model. However, for this more general assessment, a simplified version of the model called ECOSENSELE (www.ExternE.info) is used. This model only distinguishes between the region, where the power plant is located, but not the exact site. The difference between the estimations of the simplified and the complex model lies in most cases below 10\%, which is small compared to the uncertainties of the analysis. 


\section{EPJ Web of Conferences}

\section{4. - Climate change}

The assessment of the emissions of greenhouse gases could in principal follow the impact pathway approach, e.g. by using a climate impact model to estimate marginal damage costs of the emission of greenhouse gases. If for instance the integrated assessment model of climate change FUND (http://www.fund-model.org/) is used, the resulting marginal damage costs for one additional t of $\mathrm{CO}_{2}$ released in 2030 varies between $10 €$ and $2200 €$, where the difference is mainly influenced by the assumptions about the discount rate and whether and how equity weighting is used.

This range of results is too large to be useful. Thus the impact pathway or damage cost approach cannot be used here. Instead, we use the statement of the theory of environmental economics that in the pareto optimal state marginal damage costs are equal to marginal avoidance costs, i.e. we substitute marginal damage costs by marginal avoidance costs to reach an agreed environmental aim.

For our first scenario we use EU's long-term aim for greenhouse gas reduction, stating that the increase of the global average surface temperature should not increase by more than $2^{\circ}$ compared to preindustrial times. This can be translated in a maximum concentration of greenhouse gases in the atmosphere of $450 \mathrm{ppm} \mathrm{CO}_{2}$-equivalent. A meta study of Kuik et al. [9] shows, that in order to not exceed this concentration marginal avoidance costs of ca. $250 €_{2010} / \mathrm{t} \mathrm{CO}_{2 \text {,eq }}$ occur in 2050. In a second scenario, we assume that the international community cannot reach a global agreement about fulfilling the $2^{\circ}$ aim. Thus we restrict EU's ambition to fulfilling the greenhouse gas reduction aim of the EU for 2020, i.e. $20 \%$ reduction 2020 compared to 1990, and further assume a moderate extrapolation of this aim after 2020. The marginal avoidance costs to reach these aims are shown in table III.

TABLE III. - Marginal avoidance costs per $t$ of $\mathrm{CO}_{2, \text { eq }}$ for reaching agreed reduction aims.

\begin{tabular}{|l|c|c|c|c|c|c|}
\hline Reduction aim & 2010 & 2015 & 2025 & 2035 & 2045 & 2050 \\
\hline $20 \%$ plus $\left[€_{2010}\right.$ per t $\left.\mathrm{CO}_{2, \mathrm{eq}}\right]$ & 26 & 30 & 36 & 42 & 74 & 87 \\
\hline $2^{\circ} \max \left[€_{2010}\right.$ per t $\left.\mathrm{CO}_{2, \mathrm{eq}}\right]$ & 36 & 46 & 73 & 119 & 194 & 250 \\
\hline
\end{tabular}

This assessment is quite straight forward. If we would take the marginal avoidance costs into account for each decision, which involves a change in greenhouse gas emissions, we would automatically, i.e. driven by the market, achieve the greenhouse gas reduction aim. For our example, the assessment of power plants, we would thus assess each $t$ of $\mathrm{CO}_{2, \text { eq }}$ released in 2025 by $36 €$ per $\mathrm{t}$ resp. $73 €$ per $\mathrm{t}$.

\section{5. - Social electricity generating costs}

In the previous chapters, we have estimated the costs, the back-up costs, the impacts on human health and ecosystems and the impacts caused by greenhouse gas emissions. Furthermore, we have transformed the non-monetary impacts into monetary values using 


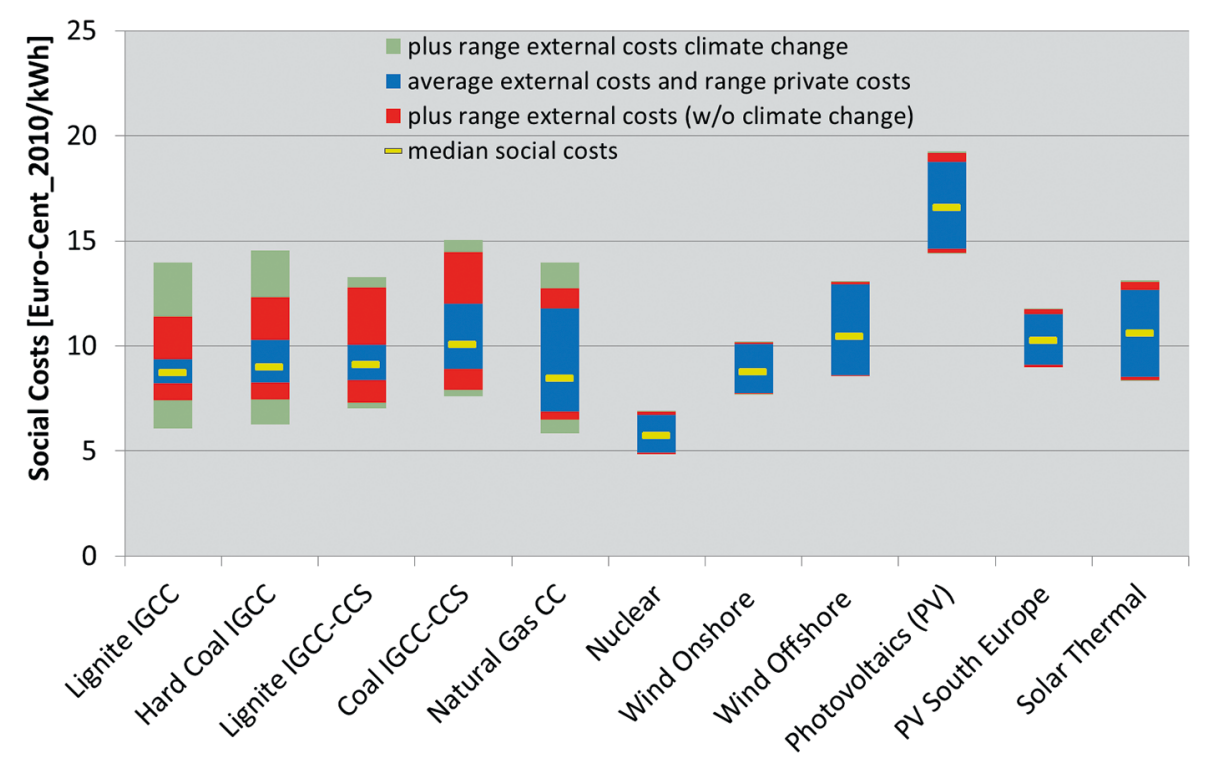

Fig. 4. - Social costs of electricity generation for new future power plants built 2025. GHG assessment with marginal avoidance costs to reach the " $20 \%$ plus" aim.

the willingness to pay or the marginal avoidance cost approach. In addition, for all three cost categories, a standard deviation around the average value has been estimated. Thus we can now add the estimated monetary impacts, the sum are the "social costs". Social costs thus express the performance of techniques with regard to the three most relevant criteria low costs, small environmental and health impacts caused by air pollution and climate protection.

Figure 4 shows the social costs for the less ambitious climate protection aim, i.e. the $20 \%$ plus aim.

What is shown by the bars is the uncertainty range of costs, environmental and health impacts and avoidance costs for greenhouse gas reductions. Nuclear energy turns out to have the lowest social costs, as health impacts and greenhouse gas emissions are both very small. Of course some societies have decided, that they would not want to bear the imagination of a large nuclear accident with very severe damages happening in their countries, even if the probability is very low. This has to be respected, so that for these societies nuclear power plants would not be an option despite the low social costs. Social costs with plants fired with fossil fuels are obviously close together, gas plants may have the lowest social costs, but this depends heavily on the assumptions of the future gas price. Onshore wind energy obviously can compensate the higher costs with lower GHG emissions and less air pollution impacts. Plants with CCS have slightly higher social costs than plants without CCS, thus with a moderate ambition for climate protection CCS might not be an option. Wind offshore has higher social costs than wind onshore, $\mathrm{PV}$ in central and Northern Europe is not an advantageous option. 


\section{EPJ Web of Conferences}

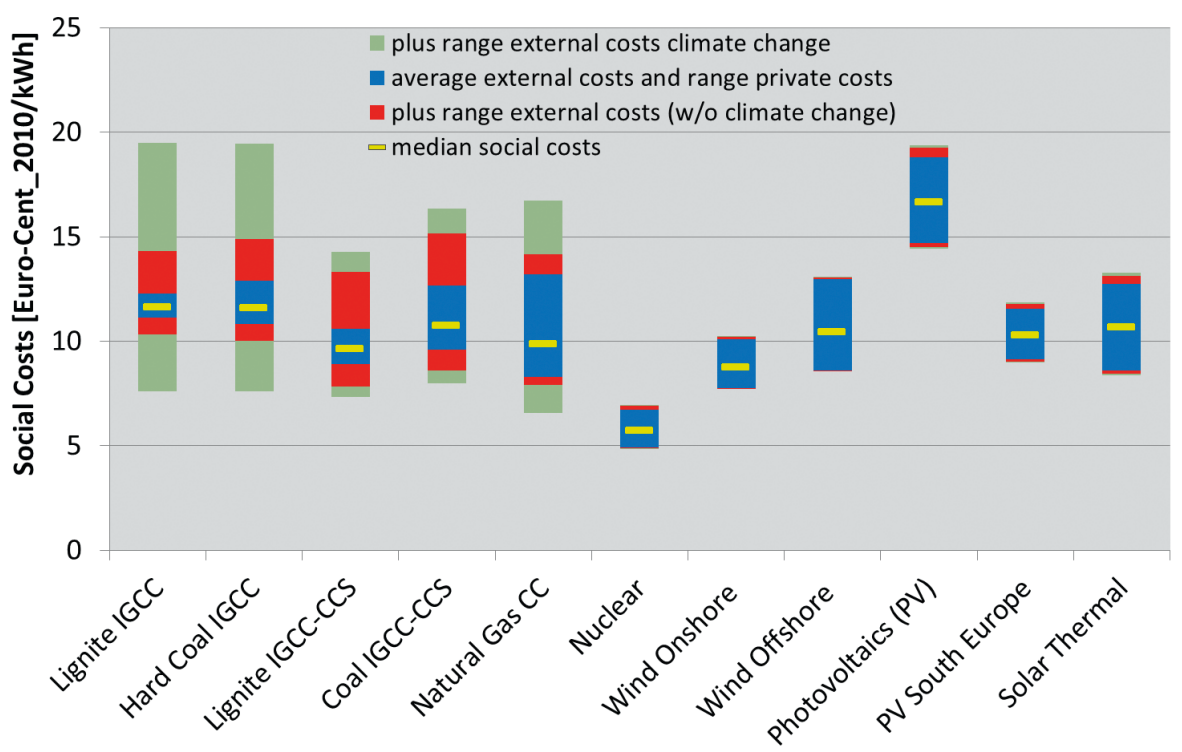

Fig. 5. - Social costs of electricity generation for new future power plants built 2025.GHG assessment with marginal avoidance costs to reach the " $2^{\circ}$ " aim.

Figure 5 shows the social costs for the much tighter $2^{\circ}$ aim.

Now the influence of the GHG emissions is higher, thus coal fired plants with CCS have lower social costs than those without CCS. Wind onshore is now the best option (apart from nuclear, where accepted). Wind offshore and solar energy in Southern countries have social costs that are comparable with those of coal fired plants with CCS and with gas plants - if the gas price stays low.

\section{6. - Conclusions}

As decisions in the energy field, that are based on an intuitive accounting of information, often fail to provide solutions, that lead to an optimal welfare of the society, a quantitate decision support system, that includes the weighting of the degree of fulfilment of the different criteria relevant for the decision should be used. The "impact pathway approach" is a tool for integrated assessment of technologies and policies, whose basic element is the weighing of criteria based on the measurement of the preferences of the affected population. A web-based tool and more information can be found on www. externe.info and www.integrated-assessment.eu.

An exemplary study applying methodology and tool was carried out and revealed the following conclusions:

An electricity generating system with low social costs, but an ambitious climate policy $\left(2^{\circ}\right.$ aim), would contain a mix of nuclear, onshore and offshore wind, run-off water (not shown here), solar energy in the South, lignite and coal with CCS and natural gas plants. 


\section{LNES 2014}

However, nuclear (EPR from now on, Generation IV after 2030) would not be accepted in some countries due to risk aversion; the problem of nuclear waste disposal might be reduced by progress in transmutation. With natural gas, there is an issue with energy supply security, furthermore the price might increase. The environmental and economic risks of carbon storage are yet uncertain.

Biomass burnt in smaller plants has relatively high external and social costs (and is anyway needed for the production of liquid fuels). The use of residual biomass in large plants might be a favourable option. With a moderate climate strategy, lignite and hard coal without CCS might play a certain (limited) role.

\section{REFERENCES}

[1] Kahneman D., Thinking, Fast and Slow (Farrar, Straus and Giroux) 2011, ISBN 9780374275631.

[2] European Commission, ExternE - Externalities of Energy: Methodology 2005 Update. Institut für Energiewirtschaft und Rationelle Energieanwendung (IER), Universität Stuttgart, Germany. EUR 21951 (Office for Official Publications of the European Communities, Luxembourg) 2005. ISBN 92-79-00423-9, ExternE Methodolody 2005 Update, http://www.externe.info/brussels/methup05a.pdf.

[3] Unified EMEP Model, (2003) Unified EMEP Model Description, http://www.emep. int/index model.html.

[4] Torfs R., Hurley F., Miller B. and Rabl A., "A set of concentration-response functions", NEEDS project, FP6, Rs1b_D3.7 - Project no: 502687, 2007, in NEEDS project, FP6, Rs1b_D3.7 - Project no: 502687.

[5] HEIMTSA, "Health and Environment Integrated Methodology and Toolbox for Scenario Assessment", EU FP6, Contract number: GOCE-CT-2006-036913-2, 2007-2011, http:// www.heimtsa.eu/.

[6] World Health Organization, "Health risks of air pollution in Europe - HRAPIE project: Recommendations for concentration-response functions for cost-benefit analysis of particulate matter, ozone and nitrogen dioxide" (WHO Regional Office for Europe, Copenhagen) 2013; http://www.euro.who.int/_data/assets/pdf_file/0006/238956/ Health-risks-of-air-pollution-in-Europe-HRAPIE-project, -Recommendations-forconcentrationresponse-functions-for-costbenefit-analysis-of-particulatematter,-ozone-and-nitrogen-dioxide.pdf?ua=1.

[7] Ott W., Baur M., Kaufmann Y., Frischknecht R. and Steiner R., "Assessment of Biodiversity Losses". NEEDS Deliverable D.4.2.-RS1b/WP4 (2006) http://www.needsproject.org/RS1b/RS1b_D4.2.pdf.

[8] Friedrich R. (Editor), "HEATCO - Developing Harmonised European Approaches for Transport Costing and Project Assessment" (IER, Germany) http://heatco.ier.unistuttgart.de/.

[9] Kuik O., Brander L. and Tol R., "Marginal abatement costs of greenhousegas emissions: A meta-analysis", Energy Policy, 37 (2009) 1395-1403, doi:10.1016/j.enpol. 2008.11.040. 